\title{
Article
}

\section{Effects of footwear designed to boost energy return on running economy icompared to traditional running shoes}

Sinclair, Jonathan Kenneth, Mcgrath, Rebecca, Brook, Oliver, Taylor, Paul John and Dillon, Stephanie

Available at http://clok.uclan.ac.uk/12430/

Sinclair, Jonathan Kenneth ORCID: 0000-0002-2231-3732, Mcgrath, Rebecca, Brook, Oliver, Taylor, Paul John ORCID: 0000-0002-9999-8397 and Dillon, Stephanie ORCID: 0000-0002-3369-8199 (2015) Effects of footwear designed to boost energy return on running economy icompared to traditional running shoes. Journal of sport sciences, 7 (1). S77-S58.

It is advisable to refer to the publisher's version if you intend to cite from the work. http://dx.doi.org/10.1080/19424280.2015.1038618

For more information about UCLan's research in this area go to

http://www.uclan.ac.uk/researchgroups/ and search for <name of research Group>.

For information about Research generally at UCLan please go to http://www.uclan.ac.uk/research/

All outputs in CLoK are protected by Intellectual Property Rights law, including Copyright law. Copyright, IPR and Moral Rights for the works on this site are retained by the individual authors and/or other copyright owners. Terms and conditions for use of this material are defined in the policies page. 


\section{PROOF COVER SHEET}

Journal acronym: RJSP

Author(s): $\quad$ J. Sinclair, R. Mcgrath, O. Brook, P. J. Taylor and S. Dillon

Article title: Influence of footwear designed to boost energy return on running economy in comparison to a conventional running shoe

Article no: $\quad 1088961$

Enclosures: 1) Query sheet

2) Article proofs

\section{Dear Author,}

1. Please check these proofs carefully. It is the responsibility of the corresponding author to check these and approve or amend them. A second proof is not normally provided. Taylor \& Francis cannot be held responsible for uncorrected errors, even if introduced during the production process. Once your corrections have been added to the article, it will be considered ready for publication.

Please limit changes at this stage to the correction of errors. You should not make trivial changes, improve prose style, add new material, or delete existing material at this stage. You may be charged if your corrections are excessive (we would not expect corrections to exceed 30 changes).

For detailed guidance on how to check your proofs, please paste this address into a new browser window: http://journalauthors.tandf.co.uk/production/checkingproofs.asp

Your PDF proof file has been enabled so that you can comment on the proof directly using Adobe Acrobat. If you wish to do this, please save the file to your hard disk first. For further information on marking corrections using Acrobat, please paste this address into a new browser window: http://journalauthors.tandf.co.uk/production/acrobat.asp

2. Please review the table of contributors below and confirm that the first and last names are structured correctly and that the authors are listed in the correct order of contribution. This check is to ensure that your name will appear correctly online and when the article is indexed.

\begin{tabular}{|l|l|l|l|l|}
\hline Sequence & Prefix & Given name(s) & Surname & Suffix \\
\hline 1 & & J. & Sinclair & \\
\hline 2 & & R. & Mcgrath & \\
\hline 3 & & O. & Brook & \\
\hline 4 & & P. J. & Taylor & \\
\hline 5 & & S. & Dillon & \\
\hline
\end{tabular}


Queries are marked in the margins of the proofs, and you can also click the hyperlinks below.

Content changes made during copy-editing are shown as tracked changes. Inserted text is in red font and revisions have a red indicator $\curlywedge$. Changes can also be viewed using the list comments function. To correct the proofs, you should insert or delete text following the instructions below, but do not add comments to the existing tracked changes.

\section{AUTHOR QUERIES}

\section{General points:}

1. Permissions: You have warranted that you have secured the necessary written permission from the appropriate copyright owner for the reproduction of any text, illustration, or other material in your article. Please see http://journalauthors.tandf.co.uk/permissions/usingThirdPartyMaterial.asp.

2. Third-party content: If there is third-party content in your article, please check that the rightsholder details for re-use are shown correctly.

3. Affiliation: The corresponding author is responsible for ensuring that address and email details are correct for all the co-authors. Affiliations given in the article should be the affiliation at the time the research was conducted. Please see http://journalauthors.tandf.co.uk/preparation/writing.asp.

4. Funding: Was your research for this article funded by a funding agency? If so, please insert 'This work was supported by <insert the name of the funding agency in full>', followed by the grant number in square brackets '[grant number xxxx]'.

5. Supplemental data and underlying research materials: Do you wish to include the location of the underlying research materials (e.g. data, samples or models) for your article? If so, please insert this sentence before the reference section: 'The underlying research materials for this article can be accessed at $<$ full link $>$ / description of location [author to complete]'. If your article includes supplemental data, the link will also be provided in this paragraph. See <http://journalauthors.tandf.co.uk/preparation/multimedia.asp > for further explanation of supplemental data and underlying research materials.

6. The CrossRef database (www.crossref.org/) has been used to validate the references. Changes resulting from mismatches are tracked in red font.

AQ1 Please check and confirm if the inserted city name for the affiliations and in the address for correspondence is correct.

AQ2 Please spell out ' $\mathrm{VO}_{2}$ ' in full first mention.

AQ3 The year for "Hanson et al., 2010" has been changed to 2011 to match the entry in the references list. Please provide revisions if this is incorrect.

AQ4 The reference "Cavanagh \& Lafortune, 1980" is cited in the text but is not listed in the references list. Please either delete in-text citation or provide full reference details following journal style [http://www.tandf.co.uk/ journals/authors/style/reference/tf_APA.pdf].

AQ5 The disclosure statement has been inserted as per journal style. Please correct if this is inaccurate.

AQ6 Please provide missing volume number/page number for the "Fuller et al., 2014" references list entry. 


\section{How to make corrections to your proofs using Adobe Acrobat/Reader}

Taylor \& Francis offers you a choice of options to help you make corrections to your proofs. Your PDF proof file has been enabled so that you can mark up the proof directly using Adobe Acrobat/Reader. This is the simplest and best way for you to ensure that your corrections will be incorporated. If you wish to do this, please follow these instructions:

1. Save the file to your hard disk.

2. Check which version of Adobe Acrobat/Reader you have on your computer. You can do this by clicking on the "Help" tab, and then "About".

If Adobe Reader is not installed, you can get the latest version free from http://get.adobe.com/reader/.

3. If you have Adobe Acrobat/Reader 10 or a later version, click on the "Comment" link at the right-hand side to view the Comments pane.

4. You can then select any text and mark it up for deletion or replacement, or insert new text as needed. Please note that these will clearly be displayed in the Comments pane and secondary annotation is not needed to draw attention to your corrections. If you need to include new sections of text, it is also possible to add a comment to the proofs. To do this, use the Sticky Note tool in the task bar. Please also see our FAQs here: http://journalauthors.tandf.co.uk/production/index.asp.

5. Make sure that you save the file when you close the document before uploading it to CATS using the "Upload File" button on the online correction form. If you have more than one file, please zip them together and then upload the zip file.

If you prefer, you can make your corrections using the CATS online correction form.

\section{Troubleshooting}

Acrobat help: http://helpx.adobe.com/acrobat.html

Reader help: http://helpx.adobe.com/reader.html

Please note that full user guides for earlier versions of these programs are available from the Adobe Help pages by clicking on the link "Previous versions" under the "Help and tutorials" heading from the relevant link above. Commenting functionality is available from Adobe Reader 8.0 onwards and from Adobe Acrobat 7.0 onwards.

Firefox users: Firefox's inbuilt PDF Viewer is set to the default; please see the following for instructions on how to use this and download the PDF to your hard drive:

http://support.mozilla.org/en-US/kb/view-pdf-files-firefox-without-downloading-them\#w_using-a-pdf-reader-plugin 


\title{
Influence of footwear designed to boost energy return on running economy in comparison to a conventional running shoe
}

\author{
J. Sinclair ${ }^{\mathrm{a}}$, R. Mcgrath ${ }^{\mathrm{a}}$, O. Brook ${ }^{\mathrm{a}}$, P. J. Taylor ${ }^{\mathrm{b}}$ and S. Dillon ${ }^{\mathrm{c}}$
}

aDivision of Sport Exercise and Nutritional Sciences, School of Sport Tourism and Outdoors, University of Central Lancashire, Lancashire, UK; bSchool of Psychology, University of Central Lancashire, Lancashire, UK; International Institute of Nutritional Science and Food Safety Studies, School of Sport Tourism and Outdoors, University of Central Lancashire, Lancashire, UK

\section{ABSTRACT}

Running economy is a reflection of the amount of inspired oxygen required to maintain a given velocity and is considered a determining factor for running performance. Athletic footwear has been advocated as a mechanism by which running economy can be enhanced. New commercially available footwear has been developed in order to increase energy return, although their efficacy has not been investigated. This study aimed to examine the effects of energy return footwear on running economy in relation to conventional running shoes. Twelve male runners completed 6-min steady-state runs in conventional and energy return footwear. Overall, $\mathrm{VO}_{2}$, heart rate, respiratory exchange ratio, shoe comfort and rating of perceived exertion were assessed. Moreover, participants subjectively indicated which shoe condition they preferred for running. Differences in shoe comfort and physiological parameters were examined using Wilcoxon signed-rank tests, whilst shoe preferences were tested using a chi-square analysis. The results showed that $\mathrm{VO}_{2}$ and respiratory exchange ratio were significantly lower, and shoe comfort was significantly greater, in the energy return footwear. Given the relationship between running economy and running performance, these observations indicate that the energy return footwear may be associated with enhanced running performance in comparison to conventional shoes.

\section{Introduction}

Running economy is defined as the steady-state oxygen consumption $\left(\mathrm{VO}_{2}\right)$ required to maintain a given running velocity (Morgan, Martin, \& Krahenbuhl, 1989). The economy of running is considered to be a principal determining factor of running performance (Cavanagh \& Williams, 1982). It has been demonstrated that running economy is a better predictor of distance running performance than $\mathrm{VO}_{2}$ max (Hanson, Berg, Deka, Meendering, \& Ryan, 2011). Therefore, improvements in running economy are of significant interest to runners, and this area has received considerable research attention.

Athletic footwear has been advocated as a mechanism by which running economy can be improved (Frederick, Howley, \& Powers, 1986). The current consensus in footwear biomechanics literature is that running economy can be enhanced by footwear with appropriate mechanical characteristics (Sinclair, Taylor, Edmundson, Brooks, \& Hobbs, 2014b). A variety of different shoe parameters including midsole cushioning, comfort, rearfoot control, midsole longitudinal stiffness, mass and midsole viscoelasticity have been proposed to modify running economy (Fuller, Bellenger, Thewlis, Tsiros, \& Buckley, 2014).

Recent research into the effects of footwear on running economy has focussed heavily on the effects of running barefoot in relation to conventional running shoes. Hanson et al. (2011) and Squadrone and Gallozzi (2009) demonstrated that running barefoot was associated with significant reductions in the oxygen cost of running in comparison to a shod condition. Moore, Jones, and Dixon (2014) examined the effects of barefoot, minimalist and conventional footwear on running economy. Their findings confirmed that running barefoot significantly improved running economy compared to both minimalist and conventional footwear. However, because shoe mass has been shown to increase the oxygen cost of running for a given workload (Franz, Wierzbinski, \& Kram, 2012), studies of this nature have been criticised. Franz et al. (2012) placed additional mass equal to the weight of the running shoe onto the foot and examined the effects of barefoot and shod conditions on the oxygen cost of running. Their findings showed that when the effects of shoe mass were controlled, the oxygen cost of running was significantly greater when running barefoot.

Some investigations have shown that the midsole characteristics of the running shoe can influence the economy of running. Bosco and Rusko (1983) examined the effects of a shock-attenuating viscoelastic insert. Their results served to increase running economy during treadmill running in comparison to running in the same footwear without the viscoelastic insert. Frederick et al. (1986) reported that running in a 
75 shoe with a gas-inflated cushioning system significantly increased running economy during treadmill running by 2.4\% when compared with a conventional running shoe. Worobets, Wannop, Tomaras, and Stefanyshyn (2014) investigated the effects of a soft shoe and control shoe on running economy during both overground and treadmill running. Their findings confirmed that soft shoes produced significant improvements in running economy during both conditions. Luo, Stergiou, Worobets, Nigg, and Stefanyshyn (2009) examined the effects of footwear with different levels of subjectively rated comfort of steady-state $\mathrm{VO}_{2}$. They showed that the most comfortable footwear conditions significantly reduced steady-state $\mathrm{VO}_{2}$.

Conversely, Nigg, Stefanyshyn, Cole, Stergiou, and Miller (2003) examined the influence of footwear with distinct mid-

90 sole material characteristics on muscle activation and running economy, and their findings confirmed that wearing viscoelastic, as opposed to hard, midsoles did not significantly influence steady-state $\mathrm{VO}_{2}$. Sinclair et al. (2014b) investigated the effects of footwear with different midsole cushioning properties on running economy. Their observations similarly showed that distinct footwear cushioning properties did not significantly influence running economy.

New commercially available footwear has been recently released that utilises a thermoplastic polyurethane midsole, rather than more conventional ethylene vinyl acetate materials. This new midsole material is claimed by the manufacturer to be able to promote energy return in comparison to traditional ethylene-vinyl-acetate-based footwear midsoles. Only 1 study has investigated the efficacy of these new energy return footwear. Sinclair, Franks, Fau-Goodwin, Naemi, and Chockalingam (2014a) examined the kinetics and 3-dimensional (3-D) lower extremity kinematics of running in energy return and conventional running shoes. Their results indicated that tibial accelerations, peak eversion and tibial internal rotation parameters were significantly greater in the energy return footwear. Given that both tibial accelerations and ankle eversion are linked to the aetiology of chronic pathologies (Eslami, Begon, Farahpour, \& Allard, 2007; Taunton, Clement, \& McNicol, 1982; Whittle, 1999), this led to the conclusion that the energy return footwear may place runners at an increased risk of injury.

There is no published information regarding the influence of these new commercially available footwear designed to increase energy return on the economy of running. Therefore, the aim of the current study was to comparatively explore the effects of energy return footwear on the oxygen cost of steady-state running in relation to conventional running shoes. This study tests the hypothesis that energy return footwear serve to reduce the oxygen cost of running.

\section{Methods}

\section{Participants}

Twelve male runners volunteered to take part in this study. The mean characteristics of the participants were: age $22.4 \pm 2.2$ years, height $176.1 \pm 5.3 \mathrm{~cm}$ and body mass $73.5 \pm 6.2 \mathrm{~kg}$. Participants were active runners engaging in training at least 3 times per week $\left(\geq 35 \mathrm{~km} \cdot\right.$ week $\left.^{-1}\right)$ and with previous experience of treadmill running. Pilot work in our laboratory confirmed that all participants exhibited a rearfoot strike pattern as they demonstrated an impact peak in their vertical ground reaction force time-curve (Cavanagh \& Lafortune, 1980). All were free from pathology at the time of data collection, and written informed consent for study participation was provided by the participants in accordance with the Declaration of Helsinki. The study procedure was approved by a university ethics committee.

\section{Procedure}

Participants ran at $12 \mathrm{~km} \cdot \mathrm{h}^{-1}$ on an HP Cosmos treadmill (Quasar, HP Cosmos, Nussdorf-Traunstein) maintained with a $0 \%$ incline. Treadmill velocity was validated prior to the commencement of data collection in accordance with the protocol of Sinclair et al. (2014b) and found to be $>99.9 \%$ accurate. In agreement with the procedure documented by Hanson et al. (2011), participants were required to undertake a 3 -min habituation period in both footwear conditions during which they ran at the required velocity prior to the commencement of data collection.

Respiratory gases were collected throughout testing using the MetaLyser 3B system (Cortex Biophysic, Leipzig, Germany). Heart rate was monitored using a Polar heart rate monitor (Polar Electro Oy, Kempele, Finland). Prior to the commencement of each testing session, the Metalyser system was calibrated. This firstly involved inputting the atmospheric pressure, following which the pneumotach volume sensor was also calibrated using a $3.0 \mathrm{~L}$ syringe (Hans Rudolph Inc., Kansas (ity, USA). Lastly, the gas sensors were calibrated using ambient air and known gas concentrations of $5.09 \% \mathrm{O}_{2}$ and $14.46 \% \mathrm{CO}_{2}$. In order to eliminate the potential variation in $\mathrm{VO}_{2}$ due to circadian rhythmicity, each data collection session was conducted at the same time of day. The data collection protocol consisted of $6 \mathrm{~min}$ steady-state runs in agreement with Nigg et al. (2003). Participants were required to attend the laboratory a minimum of $4 \mathrm{~h}$ postprandial, and the order of wearing each type of footwear was randomised to prevent any order effects (Frederick et al., 1986). Participants completed their runs in both shoe conditions within the same testing session, with rest in between; 1 trial was conducted in each type of footwear. The subsequent testing condition was not started until the participants' heart rate was less than 110 beats per minute and they felt ready to undertake further analysis (Hanson et al., 2011). The test-retest reliability of the metalyzer for this protocol observed has been investigated previously and was shown to be very good $\left(R^{2}=0.95\right)$ (Sinclair et al., 2014b).

From the experimental data key measurements of mean $\mathrm{VO}_{2}\left(\mathrm{ml} \cdot \mathrm{kg} \cdot \mathrm{min}^{-1}\right)$, the respiratory exchange ratio (RER) and heart rate (BPM) were obtained. In addition, participants were asked to rate their perceived exertion (RPE) using the 6-20 point Borg scale at 2 min intervals. After each 6 min run, participants were asked to provide their rating of the comfort of each shoe. The comfort measurement procedure consisted of a $150 \mathrm{~mm}$ visual analogue scale, with the extreme left side being indicative of "not comfortable at all" and the extreme right of the scale labelled as "most comfortable condition 
imaginable" (Mündermann, Nigg, Stefanyshyn, \& Humble, 2002). Upon conclusion of the data collection, participants were also asked to subjectively indicate which shoe condition they preferred for running.

\section{Experimental footwear}

The running shoes used during the current investigation consisted of conventional footwear (Saucony pro grid guide II) and commercially available footwear which claims to boost energy footwear (Adidas Energy Boost), (shoe size 8-10 UK men's). As the energy return footwear were slightly lighter than the conventional running trainers, lead tape was applied in a pattern that maintained 3-D static balance until it reached the same mass (Sinclair et al., 2014b).

\section{Statistical analyses}

Differences between footwear were examined using Wilcoxon signed-rank tests. The alpha criterion for statistical significance was adjusted to $P \leq 0.008$ using a Bonferroni correction to control type I error. Effect sizes were calculated using eta ${ }^{2}\left(\eta^{2}\right)$. Finally, a chi-squared $\left(x^{2}\right)$ test was utilised to test the assumption that an equal number of participants would subjectively favour each of the footwear conditions. All statistical actions were conducted using SPSS v22.0 (SPSS Inc, Chicago, USA), and the results are presented as mean \pm standard deviations and $95 \%$ confidence intervals.

\section{Results}

\section{$\mathrm{VO}_{2}$ and $\mathrm{RER}$}

The results indicate that $\mathrm{VO}_{2}$ was significantly lower $(\mathrm{Z}=2.67$, $\left.P=0.008, \eta^{2}=0.48\right)$ in the energy return footwear in comparison to the conventional footwear (Table I). The individual differences are presented in Figure $1(\mathrm{a}) ; 10$ of the 12 participants exhibited reductions in $\mathrm{VO}_{2}$ in the energy return footwear. In addition, it was shown that the RER was significantly lower $\left(Z=2.69, P=0.007, \eta^{2}=0.46\right)$ in the energy return in comparison to the conventional footwear (Table I). Individual differences are presented in Figure 1(b), and 9 of the 12 participants exhibited reductions in the RER in the energy return footwear.

\section{Heart rate and rating of perceived exertion}

No significant differences $(P>0.008)$ were observed between footwear for either heart rate or rating of perceived exertion (Table I).

\section{Shoe comfort and preference}

The results indicate that participants rated the energy return as being significantly more comfortable $(Z=2.75, P=0.006$, $\left.\eta^{2}=0.49\right)$ than conventional footwear (Table I). In addition, the chi-squared analysis showed that there was no significant difference in footwear preference $\left(x^{2}(1)=3.80, P>0.05\right)$, with 5 participants indicating that they preferred the energy return footwear and 5 who preferred the conventional footwear.

Table I. Means, standard deviations and confidence intervals of the physiological and shoe comfort parameters for each footwear condition.

\begin{tabular}{|c|c|c|c|c|c|c|c|}
\hline & \multicolumn{3}{|c|}{ Energy return } & \multicolumn{3}{|c|}{ Conventional } & \multirow[b]{2}{*}{$\%$ Change $(95 \% \mathrm{Cl})$} \\
\hline & Mean & $S D$ & $95 \% \mathrm{Cl}$ & Mean & $S D$ & $95 \% \mathrm{Cl}$ & \\
\hline $\mathrm{VO}_{2}\left(\mathrm{ml} \cdot \mathrm{kg} \cdot \mathrm{min}^{-1}\right)$ & 41.8 & 3.2 & $39.8-43.8$ & 43.6 & 3.7 & $40.9-46.2$ & $4.2(1.4-6.8) *$ \\
\hline RER & 0.98 & 0.08 & $0.93-1.02$ & 0.99 & 0.06 & $0.95-1.03$ & $1.7(0.3-3.0) *$ \\
\hline Heart rate (BPM) & 159.6 & 16.3 & $149.3-169.9$ & 158.9 & 18 & $147.5-170.3$ & $0.5(-4.6-5.6)$ \\
\hline RPE & 10.5 & 1.3 & $9.7-11.3$ & 11.0 & 1.9 & $9.8-12.2$ & $5.4(-1.5-11.6)$ \\
\hline Comfort & 12.0 & 1.9 & $10.8-13.2$ & 10.1 & 2.9 & $8.1-11.9$ & $15.8(5.5-28.4) *$ \\
\hline
\end{tabular}

Note: ${ }^{*}=$ significant difference.
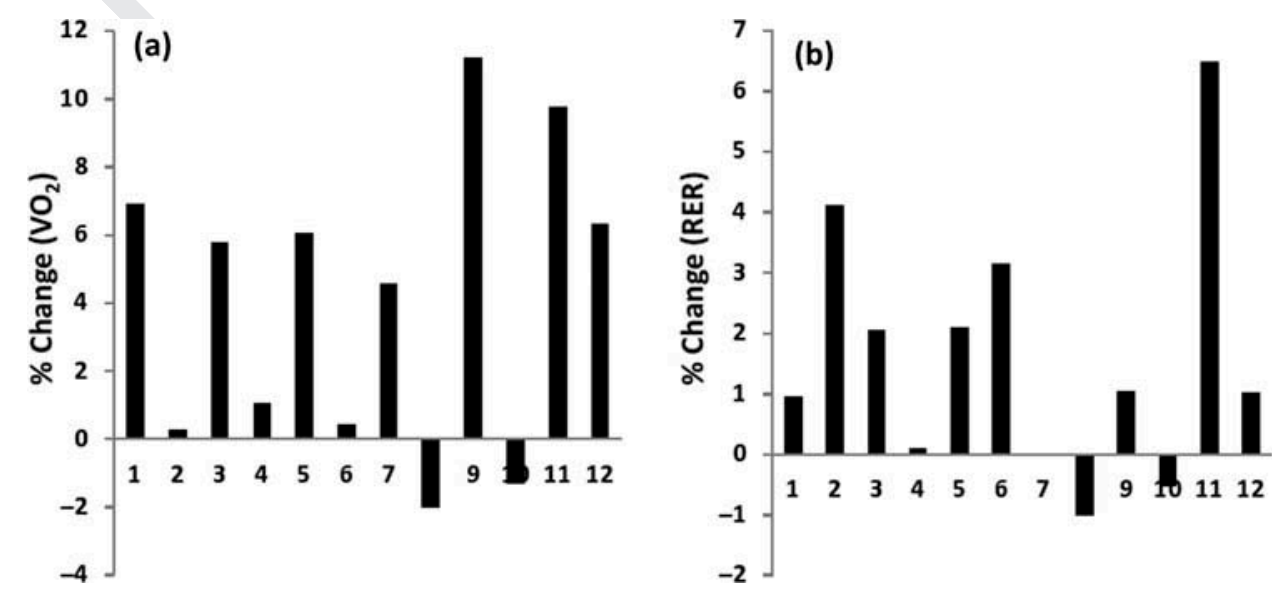

Figure 1. Individual percentage differences in (a) $\mathrm{VO}_{2}$ and (b) RER between the energy return and conventional footwear. Positive values indicate that $\mathrm{VO}_{2}$ and $\mathrm{RER}$ were lower in the energy return footwear. 


\section{Discussion}

The current investigation aimed to examine the influence of new commercially available footwear designed to increase energy return on the economy of steady-state treadmill running. This represents the first study to investigate the effects of these new footwear on the oxygen cost of running. A study of this nature may provide important information regarding the effects of different running footwear on running performance.

The first key observation from the current study was that the energy return footwear were associated with significant reductions in steady-state $\mathrm{VO}_{2}$, with 10 of the 12 participants exhibiting reductions in these shoes. This observation provides support for the hypothesis and concurs with the results of Frederick et al. (1986), Bosco and Rusko (1983) and Worobets et al. (2014), who found that different footwear significantly influenced steadystate $\mathrm{VO}_{2}$. Given the proposed inverse relationship between steady-state $\mathrm{VO}_{2}$ and running performance, it appears, based on these observations, that the energy return footwear may be associated with increases in running performance in comparison to conventional shoes. The mechanisms behind this improvement in the energy return footwear cannot be exactly pinpointed. It can be speculated that the increase in returned energy mediated by the energy return footwear served to reduce the oxygen required to maintain experimental running velocity. The influence of the different footwear conditions on $\mathrm{VO}_{2}$ can be contextualised by taking the observed differences and examining their influence on performance. Burkett, Kohrt, and Buchbinder (1985) demonstrated that every $1.0 \%$ increase in steady-state $\mathrm{VO}_{2}$ mediated a subsequent $0.17 \mathrm{~km} \cdot \mathrm{h}^{-1}$ reduction in running velocity. Therefore, the application of the $4 \%$ reduction in $\mathrm{VO}_{2}$ observed in the current study indicates that running in the energy return footwear would translate into a $3 \mathrm{~min}$ reduction in $10 \mathrm{~km}$ time.

A further key finding is that the RER was found to be significantly lower in the energy return shoes in comparison to conventional footwear, with 9 of the 12 participants exhibiting reductions in these shoes. Although the mean difference in RER was relatively small, this, nonetheless, suggests that running in the conventional footwear favours significantly greater carbohydrate utilisation in comparison to the energy return shoes (Holloszy, Kohrt, \& Hansen, 1998). As such, this observation may also have important performance considerations as carbohydrate is the primary fuel source for endurance exercise such as running and places significant demands on the body's limited carbohydrate stores (Rapoport, 2010). Additionally, muscular contractions are mediated by a variety of metabolic substrates; but, in the context of long distance running, carbohydrate is crucial (Rapoport, 2010). This observation provides further support to the previous proposition regarding performance improvements when running in the energy return footwear. Firstly, the reduced reliance on carbohydrate may serve to delay the onset of fatigue during running or, alternatively, allow, a greater running velocity to be maintained prior to the onset of fatigue (Joyner \& Limberg, 2014).

A final key observation is that shoe comfort was shown to be significantly greater in the energy return footwear compared to conventional footwear. This observation concurs with those of
Luo et al. (2009), who found significant reductions in oxygen consumption in footwear that was subjectively related as being the most comfortable. Footwear comfort has been proposed as being a mediator of the extent of muscular mechanical work output (Nigg, 2001). It is well established that muscle activity is positively related to global oxygen consumption (Nigg et al., 2003). Thus, the increased comfort noted in the energy return footwear may provide further insight into the differences in running economy observed between the 2 running shoes.

The observations of the current investigation present an interesting paradox in footwear biomechanics. The current investigation confirms that there may be significant performance benefits when running in the energy return footwear in relation to conventional shoes. However, Sinclair et al. (2014a) showed that energy return footwear were associated with greater kinetic and kinematic parameters that have been linked to the aetiology of injury. Therefore, it appears that whilst performance may be enhanced in these footwear, they place runners at an increased risk of musculoskeletal injury.

There are some limitations to the current investigation that should be acknowledged. Firstly, whilst the addition of supplementary mass to the energy return footwear was important as shoe mass is known to significantly influence steady-state $\mathrm{VO}_{2}$ (Franz et al., 2012), this may have altered the mechanical properties of the shoe upper, which was not considered as part of the current work. In addition, whilst the mass of the experimental footwear was controlled participants own preferences in terms of their lacing strategy were not standardised. Importantly, Hagen and Hennig (2009) demonstrated that different lacing configurations significantly influenced vertical loading rates and foot plantar pressures during running. Thus, it is recommended that the current study be repeated using a more consistent lacing pattern.

In conclusion, the current investigation provides new information describing the influence of commercially available footwear, claimed to increase energy return on the economy of running. On the basis that decreased $\mathrm{VO}_{2}$ and $\mathrm{RER}$ were observed when running in the footwear which aims to increase energy return, the current investigation suggests that these new footwear may be associated with increases in running performance. This study indicates that runners interested in performance may wish to select the energy return footwear over more conventional shoe models. Future research should investigate the longterm effects of these new running shoes on the aetiology and prevalence of chronic running injuries.

\section{Disclosure statement}

No potential conflict of interest was reported by the authors.

\section{References}

Bosco C., \& Rusko H. (1983). The effect of prolonged skeletal muscle stretch-shortening cycle on recoil of elastic energy and on energy expenditure. Acta Physiologica Scandinavica, 119, 219-224.

Burkett L. N., Kohrt W. M., \& Buchbinder R. (1985). Effects of shoes and foot orthotics on $\mathrm{VO}_{2}$ and selected frontal plane knee kinematics. Medicine \& Science in Sports \& Exercise, 17, 158-163. 
Cavanagh P. R., \& Williams K. R. (1982). The effect of stride length variation on oxygen uptake during distance running. Medicine \& Science in Sports \& Exercise, 14, 30-35.

Eslami M., Begon M., Farahpour N., \& Allard P. (2007). Forefoot rearfoot coupling patterns and tibial internal rotation during stance phase of barefoot versus shod running. Clinical Biomechanics, 22, 74-80.

Franz J. R., Wierzbinski C. M., \& Kram R. (2012). Metabolic cost of running barefoot versus shod: Is lighter better. Medicine \& Science in Sports \& Exercise, 44, 1519-1525.

Frederick E. C., Howley E. T., \& Powers S. K. (1986). Lower oxygen demands of running in soft-soled shoes. Research Quarterly for Exercise \& Sport, 57, 174-177.

Fuller J. T., Bellenger C. R., Thewlis D., Tsiros M. D., \& Buckley J. D. (2014). the effect of footwear on running performance and running economy in distance runners. Sports Medicine, Epub ahead of print.

Hagen M., \& Hennig E. M. (2009). Effects of different shoe-lacing patterns on the biomechanics of running shoes. Journal of Sports Sciences, 27, 267-275.

Hanson N. J., Berg K., Deka P., Meendering J. R., \& Ryan C. (2011). Oxygen cost of running barefoot vs. running shod. International Journal of Sports Medicine, 32, 401-406.

370 Holloszy J. O., Kohrt W. M., \& Hansen P. A. (1998). The regulation of carbohydrate and fat metabolism during and after exercise. Frontiers in Bioscience, 15, 1011-1027.

Joyner M. J., \& Limberg J. K. (2014). Hitting the wall: Glycogen, glucose and the carotid bodies. The Journal of Physiology, 592, 4413-4414.

375 Luo G., Stergiou P., Worobets J., Nigg B., \& Stefanyshyn D. (2009). Improved footwear comfort reduces oxygen consumption during running. Footwear Science, 1, 25-29.

Moore I. S., Jones A., \& Dixon S. (2014). The pursuit of improved running performance: Can changes in cushioning and somatosensory feedback influence running economy and injury risk? Footwear Science, 6, 1-11.
Morgan D. W., Martin P. E., \& Krahenbuhl G. S. (1989). Factors affecting running economy. Sports Medicine, 7, 310-330.

Mündermann A., Nigg B. M., Stefanyshyn D. J., \& Humble R. N. (2002). Development of a reliable method to assess footwear comfort during running. Gait \& Posture, 16, 38-45.

Nigg B. M. (2001). The role of impact forces and foot pronation: A new paradigm. Clinical Journal of Sport Medicine, 11, 2-9.

Nigg B. M., Stefanyshyn D., Cole G., Stergiou P., \& Miller J. (2003). The effect of material characteristics of shoe soles on muscle activation and energy aspects during running. Journal of Biomechanics, 36, 569-575.

Rapoport B. I. (2010). Metabolic factors limiting performance in marathon runners. PLoS Computational Biology, 6(10), e1000960.

Sinclair J., Franks C., Fau-Goodwin J., Naemi R., \& Chockalingam N. (2014a). Influence of footwear designed to boost energy return on the kinetics and kinematics of running compared to conventional running shoes. Comparative Exercise Physiology, 10, 199-206.

Sinclair J., Taylor P. J., Edmundson C. J., Brooks D., \& Hobbs S. J. (2014b). The influence of footwear kinetic, kinematic and electromyographical parameters on the energy requirements of steady state running. Movement \& Sports Sciences, 80, 39-49.

Squadrone R., \& Gallozzi C. (2009). Biomechanical and physiological comparison of barefoot and two shod conditions inexperienced barefoot runners. Journal of Sports Medicine \& Physical Fitness, 49, 6-13.

Taunton J. E., Clement D. B., \& McNicol K. (1982). Plantar fasciitis in runners. Canadian Journal of Applied Sports Sciences, 7, 41-44.

Whittle M. W. (1999). Generation and attenuation of transient impulsive forces beneath the foot: A review. Gait \& Posture, 10, 264-275.

Worobets J., Wannop J. W., Tomaras E., \& Stefanyshyn D. (2014). Softer and more resilient running shoe cushioning properties enhance running economy. Footwear Science, 6, 147-153.

\section{5}

390

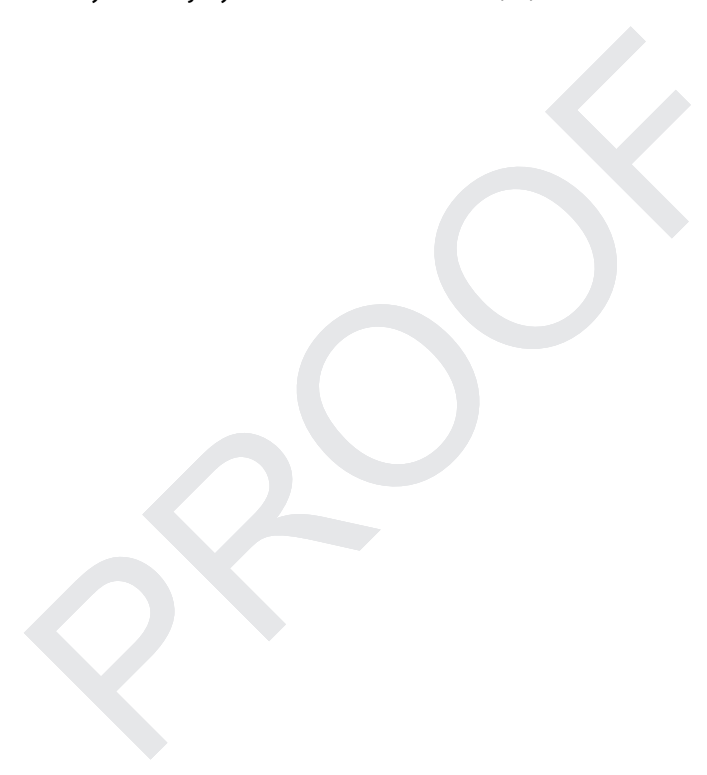

